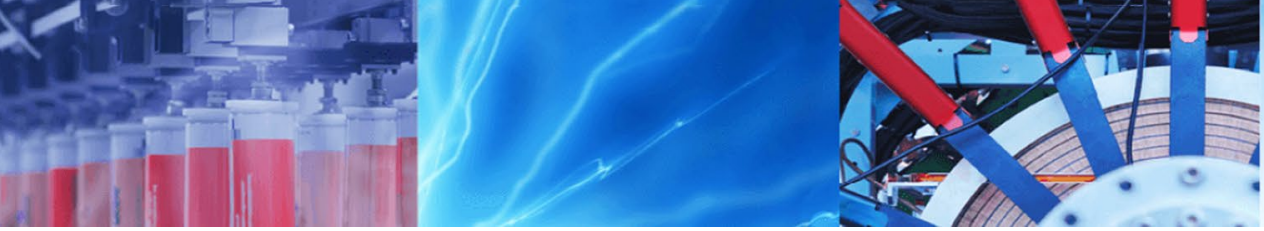

Research Article

\title{
A new spectrofluorimetric method for the determination of ascorbic acid with bromocresol purple in pharmaceutical samples
}

\author{
L. Klepo ${ }^{1}$ - M. Ascalic ${ }^{1}$ D. Medunjanin ${ }^{1} \cdot$ A. Copra-Janicijevic ${ }^{1}$
}

Received: 1 May 2021 / Accepted: 22 September 2021

Published online: 09 October 2021

(c) The Author(s) 2021 OPEN

\begin{abstract}
Based on the interaction between ascorbic acid and bromocresol purple, a new simple, straightforward, and quick method for the quantification of ascorbic acid is proposed. The procedure is based on the determined quenching effect of ascorbic acid on the natural fluorescence signal of bromocresol purple in the reaction between ascorbic acid and bromocresol purple in phosphate buffer solution $(\mathrm{pH} 6)$. The reduction of bromocresol purple fluorescence intensity is detected at $641 \mathrm{~nm}$, while excitation occurs at $318 \mathrm{~nm}$. The linear relationship between the reduced fluorescence intensity of bromocresol purple and the concentration of ascorbic acid is in the range $4.65 \times 10^{-5}$ to $4.65 \times 10^{-6} \mathrm{~mol}$ $\mathrm{L}^{-1}\left(\mathrm{R}^{2}=0.9964\right)$, with the detection limit of $8.77 \times 10^{-7} \mathrm{~mol} \mathrm{~L}^{-1}$ and quantification limit of $2.35 \times 10^{-5} \mathrm{~mol} \mathrm{~L}^{-1}$. The findings in this study further show that the new method provides good precision and repeatability, as well as satisfactory recovery values in terms of accuracy. The new method is tested on fifteen samples with different amounts of ascorbic acid and additional components. The effects of interfering components such as citrus bioflavonoids, citric acid, folic acid, paracetamol, calcium, and magnesium carbonate on the intensity of fluorescence of bromocresol purple are also investigated. The effects of interfering components such as citrus bioflavonoids (routine and hesperidin), citric acid, folic acid, paracetamol, calcium, and magnesium carbonate on the intensity of fluorescence of bromocresol purple are also investigated. The results of iodometric titration point out that the new method is effective for the determination of ascorbic acid in pharmaceutical samples.
\end{abstract}

\section{Article Highlights}

- A new spectrofluorimetric method for determination of ascorbic acid in pharmaceutical samples using bromocresol purple.
- Determination of optimal parameters for ascorbic acid determination in a variety of pharmaceutical samples.

- Examination of the influence of additional substances in the pharmaceutical samples on the analysis.

Keywords Ascorbic acid -Spectrofluorimetry · Bromocresol purple

\section{Introduction}

Ascorbic acid (AA) called vitamin $C$ is a six-carbon lactone that is synthesized withinside the liver of most mammalian species from glucose. Humans, non-human primates, and guinea pigs don't posess the enzyme gulonolactone oxidase that is crucial for the synthesis of 2-keto-I-gulonolactone, the instant precursor of ascorbic acid. As an effect of now no longer taking nutrition $\mathrm{C}$ thru diet, a deficiency state happens which manifests with a huge spectrum of

$\triangle$ L. Klepo, klepolejla@gmail.com | ${ }^{1}$ Faculty of Science Department of Chemistry, University of Sarajevo, Zmaja od Bosne 33, Sarajevo, Bosnia and Herzegovina.

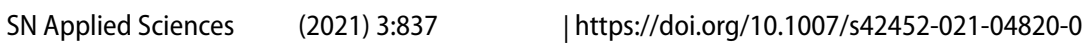


medical manifestations [1]. It is required for the manufacture of carnitine, collagen, neurotransmitters, and peptide hormones, as well as various other activities in the human body, such as hydroxylation and the oxidative catabolism of aromatic acids [2-6]. Ascorbic acid is a reducing agent because it is an electron donor. A double bond between the second and third carbons contributes two electrons. Because it gives electrons, ascorbic acid works as an antioxidant, preventing other chemicals from oxidizing. However, ascorbic acid is oxidized due to the nature of these interactions. These electrons are lost in a logical sequence. Free radicals, semi-dehydroascorbic acid, and ascorbyl radicals are the products of the loss of one electron. Ascorbyl radical is relatively stable and unreactive when compared to other free radicals [1]. As an electron donor, it scavenges free radicals directly, limits the formation of new free radicals by suppressing the NADPH oxidase (NOX) pathway, and aids in the recycling of other antioxidants [5].

Ascorbic acid is commonly found in pharmaceutical supplements, and it has a bioavailability that is comparable to that of naturally occurring ascorbic acid in meals. Sodium ascorbate, calcium ascorbate, various mineral ascorbates, ascorbic acid with bioflavonoids, and additional ascorbic acid supplements are available[7, 8].

Ascorbic acid is analyzed using a variety of procedures, with the method chosen based on cost, product use, equipment availability, and time [9]. The development of new methods for determining ascorbic acid is increasing, according to the literature, due to the large range of samples for analysis and the influence of diverse matrices [10]. Titrimetric, spectrophotometric, electrochemical, chromatographic, kinetic, chemiluminescence, and spectrofluorimetric methods have all been reported for determining ascorbic acid in various types of samples [11-13]. The main advantage of spectrofluorimetry over spectrophotometry is its sensitivity, which allows it to analyze nanogram levels of the target analyte. This method is based on the notion that the analyte under investigation can show fluorescence or can react with another substance to produce a fluorescent product [14]. Changes in fluorescence intensity that occur when the analyte is added are in the form of increasing, decreasing or strongly enhacing fluorescence signal intensity [15-22]. The measurement of decreasing fluorescence intensity of methylene blue (MB) in a spectrofluorimetric approach that uses a reaction between $M B$ and $A A$ is based on the measurement of $M B$ being reduced to colorless $L M B$ and AA being oxidized to dehydroascorbic acid (DHAA) [15]. Xanthene dyes, such as pyronine $Y$, are a type of xanthene dye. In water, it emits a bright red-yellow glow. In the presence of nitrite, its molecular structure is broken, and the fluorescence of the solution drops dramatically. When there is only a trace of ascorbic acid in the system, the reaction proceeds slowly. This demonstrates that ascorbic acid can stifle the system's reactivity. As a result, this phenomenon is utilized to determine ascorbic acid in a range of materials [16].

This paper describe new, simple, sensitive, and rapid spectrofluorimetric method for determination of ascorbic acid in pharmaceutical samples. Bromocresol purple (BCP) was chosen as the chromogenic reagent for the determination of AA in pharmaceutical samples. The effects of various reaction conditions, such as acidity, $\mathrm{BCP}$ concentration, reaction time, instrumental parameters, as well as the influence of possible interfearing substances were carefully investigated. To the best of our knowledge, there has been no report on the application of bromocresol purple for the determination of AA by a spectrofluorimetric method.

\section{Materials and methods}

\subsection{Instrumentation}

All fluorescence measurements were carried out on a lambda LS 55 luminescence spectrometer (Perkin-Elmer, Buckinghamshire, UK) equipped with a xenon lamp and a $1 \mathrm{~cm}$ quartz cell. $\mathrm{pH}$ adjustments were done on a digital $\mathrm{pH}$ meter Metler Toledo pH meter SG2 SevenGo.

\section{Reagents and solutions used for spectrophotometric determination}

All reagents used were analytical grade. A stock solution of ascorbic acid (Gram-mol, Croatia) $4.65 \times 10^{-4} \mathrm{~mol} \mathrm{~L}^{-1}$ is always prepared fresh due to the instability of AA by dissolving $0.0041 \mathrm{~g}$ of AA in a $50.0 \mathrm{~mL}$ calibrated flask and fill up to the mark with ultra-pure water (conductivity was: $0.055 \mathrm{~S} \mathrm{~cm}^{-1}$, expressed as the resistivity of $18.2 \mathrm{M} \Omega \mathrm{cm}^{-1}$ and TOC was $0.02 \mathrm{ppb})$. A stock solution of bromocresol purple (BCP) (Coleman \& Bell Co, Norway) $1 \times 10^{-4} \mathrm{~mol} \mathrm{~L}^{-1}$ is prepared by dissolving $0.0054 \mathrm{~g}$ of $\mathrm{BCP}$ in a $100.0 \mathrm{~mL}$ graduated flask and filled up to the mark with ultra-pure water. All further dilutions are made with ultra-pure water. The BCP working concentration was $1 \times 10^{-5} \mathrm{~mol} \mathrm{~L}^{-1}$. Phosphate buffer, $\mathrm{pH}=6.4$ was prepared by mixing $27.0 \mathrm{~mL}$ of dipotassium hydrogen phosphate (Merck, Germany) in a concentration of $1 \mathrm{~mol} \mathrm{~L}^{-1}$ and $72.2 \mathrm{~mL}$ of potassium dihydrogen phosphate (Semikem, Bosnia and Herzegovina) also at a concentration of $1 \mathrm{~mol} \mathrm{~L}^{-1}$. The $\mathrm{pH}$ is adjusted with $2.0 \mathrm{~mol} \mathrm{~L}^{-1}$ sodium hydroxide.

Pharmaceutical samples (tablets, powders, and effervescent tablets) used for analysis ( 15 samples) were commercially available. The solutions of pharmaceutical preparations were prepared by dissolving suitable amounts of 
the samples in a $50.0 \mathrm{~mL}$ calibrated flask and diluting to the mark with ultra-pure water.

The following commercial pharmaceutical samples in the form of tablets and powders have been analyzed by the proposed method. Table 1 shows pharmaceutical samples that were analyzed with the proposed method together with the accompanying components that can be found in tablets.

For the validation experiments, a $0.01 \mathrm{~mol} \mathrm{~L}^{-1}$ iodine solution was prepared and standardized according to the literature. The iodine method is recommended by the European Pharmacopoeia [23] as the standard method for the determination of AA in pharmaceutical preparations.

Possible interfering substances such as rutin, hesperidin, calcium carbonate, magnesium carbonate, citric acid, paracetamol, folic acid, zinc chloride, and iron(II) sulfate were examined. The influence of possible interfering substances on the relative intensity of the fluorescence signal was examined by analyzing the standard solution of AA and three different concentrations of the interfering substances. Concentrations of interfering substances were higher, the lower and same order of magnitude as the concentration of AA.

\section{General procedure for the spectrofluorimetric quantification of ascorbic acid}

An aliquot of $A A(2 \mathrm{~mL})$ of different dilutions, $B C P(2 \mathrm{~mL})$, and phosphate buffer $(1 \mathrm{~mL})$ were mixed in a $10.0 \mathrm{~mL}$ calibration flask. The volumetric flasks with different $A A$ dilutions are then incubated at $40^{\circ} \mathrm{C}$ for $15 \mathrm{~min}$ in a water bath, then left to cool to room temperature for $5 \mathrm{~min}$. The final mixture was diluted to $10.0 \mathrm{~mL}$ with ultra-pure water. After cooling for $10 \mathrm{~min}$, the relative fluorescence intensity signal was measured at working excitation and emission wavelengths ( $318 \mathrm{~nm}$ and $641 \mathrm{~nm}$ ) with a $10.0 \mathrm{~mm}$ slit width of all open filters and at $1 \%$ of transmittance $(1 \% \mathrm{~T})$. The fluorescence intensity was also measured after $30 \mathrm{~min}$ under the above-mentioned conditions.

\section{Results}

This paper informs on a new method for the determination of ascorbic acid with bromocresol purple in pharmaceutical samples that was developed. Ascorbic acid in reaction with $B C P$ is oxidized to dehydroascorbic acid (DHAA) and $B C P$ is reduced to his reduced (Leuko-BCP) form in phosphate buffer $\mathrm{pH}=6.4$ (Fig. 1). The effect of decreasing relative fluorescence intensity was used for the estimation of AA content in investigated samples.

\section{Determination of wavelength for a maximum of excitation and emission}

Excitation and emission spectra of the reagent (phosphate buffer/BCP) without $A A$ were scanned in the wavelength range of $200-800 \mathrm{~nm}$ for excitation and $200-900 \mathrm{~nm}$ for emission spectra using $10.0 \mathrm{~mm}$ slit widths and scan rates of $500 \mathrm{~nm} / \mathrm{min}$ for both spectra. Excitation peaks were observed at 318, 381, $509 \mathrm{~nm}$, and emission peaks at 320, $361,641 \mathrm{~nm}$. Then, excitation and emission spectra of the reagent with an added analyte, $\mathrm{AA}\left(4.65 \times 10^{-4} \mathrm{~mol} \mathrm{~L}^{-1}\right)$ were scanned and a decrease of intensity of fluorescence (IF) values was observed on all peaks, particularly from 895.83 to 578.75 at $318 \mathrm{~nm}$ excitation wavelength, and from 1000.07 to 826.60 at $641 \mathrm{~nm}$ emission wavelength, and these were chosen to be the working wavelengths for this method (Fig. 2).

\section{Optimization of experimental condition for the proposed method}

To optimize the proposed method, the effects of various reaction conditions, such as $\mathrm{pH}, \mathrm{BCP}$ concentration, reaction time, instrumental parameters (slits, open filters, and $1 \% \mathrm{~T}$ ) were carefully investigated. Variables were changed in the experiments one by one, while others were kept constant. Furthermore, various validation parameters such as accuracy, precision, repeatability, etc. were also investigated and calculated to prove the validity of results provided by this method.

\subsection{Influence of $\mathrm{pH}$}

The spectrophotometric measurement of AA with bromocresol purple in acidic conditions at $\mathrm{pH}=3,0$ was reported by Elgailani and Alghamdi [24]. However, this was not shown to be applicable for the spectrofluorimetric determination of $A A$. As a result, the acidity/basicity range in which the reaction occurs was tested between 3 and 8 . Between $\mathrm{pH} 5$ and 7 , the best results were obtained. So the working $\mathrm{pH}$ of the phosphate buffer was further examined by $0.2 \mathrm{pH}$ units in the range of 5 and 7 . According to the literature data for electroanalysis of ascorbic acid using poly(bromocresol purple) [25] $\mathrm{pH}, 6.4$ was the best. Our result also showed that the best reproducibly was achieved at $\mathrm{pH} 6.4$ and this $\mathrm{pH}$ was taken for further experiments.

\subsection{Influence of the concentrations of BCP}

The effect of the concentration of BCP on the relative fluorescence intensity was examined in the concentration range of $B C P$ from $1 \times 10^{-7}$ to $1 \times 10^{-4} \mathrm{~mol} \mathrm{~L}^{-1}$. The 
Table 1 Commercially available pharmaceutical samples that were analyzed

\begin{tabular}{|c|c|c|}
\hline Sample & $\begin{array}{l}\text { Pharmaceutical } \\
\text { samples of AA }\end{array}$ & Additional components \\
\hline 1 & Zink $+C$ & $\begin{array}{l}\text { Acidifier citric acid, acidity regulator sodium hydrogen carbon- } \\
\text { ate, } \mathrm{L}-\text { ascorbic acid, filler sorbitol, flavors, sweetener sodium } \\
\text { cyclamate and sodium saccharin, zinc citrate ( } 3.3 \mathrm{mg} \text { zinc), dye } \\
\text { riboflavin }\end{array}$ \\
\hline 2 & Vit $C+Z n$ & $\begin{array}{l}\text { Filler sorbitol, L-ascorbic acid (vitamin C), palm fat (completely } \\
\text { hardened), filler xylitol, acidifier citric acid, acid regulator mono- } \\
\text { sodium citrate, thickener sodium carboxymethyl cellulose, flavor, } \\
\text { zinc oxide ( } 5 \mathrm{mg} \text { ), medium-chain triglycerides, release agent } \\
\text { magnesium salts of fatty acids, sweeteners }\end{array}$ \\
\hline 3 & Eisen $+C$ & $\begin{array}{l}\text { Acidifier citric acid, acidity regulator sodium hydrogen carbonate, } \\
\text { filler sorbitol, flavors, maize starch, beetroot powder, L-ascorbic } \\
\text { acid, sweetener sodium cyclamate, and sodium saccharin, iron- } \\
\text { II-lactate, dye riboflavin }\end{array}$ \\
\hline 4 & Fabricet & $\begin{array}{l}\text { Paracetamol ( } 300 \mathrm{mg} \text { ), L-ascorbic acid, sodium hydrogen carbon- } \\
\text { ate, sodium carbonate, citric acid, lactose monohydrate, docusate } \\
\text { sodium, sodium saccharin, sodium benzoate, povidone }\end{array}$ \\
\hline 5 & Multivita plus & $\begin{array}{l}\text { Acidifier citric acid, acidity regulator sodium hydrogen carbon- } \\
\text { ate, L-ascorbic acid, filler sorbitol, inulin, sweetener sodium } \\
\text { cyclamate, maize starch, tricalcium phosphate, beetroot juice } \\
\text { powder, the aroma of orange and mango, sodium saccharin, } \\
\text { calcium-D-pantothenate, DL-alpha-tocopheryl acetate, pyridox- } \\
\text { ine hydrochloride, thiamine hydrochloride, riboflavin, petroyl- } \\
\text { mnoglutamic acid, cyanocobalamine }\end{array}$ \\
\hline
\end{tabular}
ide, talc, magnesium salts of fatty acids

$7 \quad$ Vit C Cek

Hansal Vit C 20

L-ascorbic acid (with a protective layer of ethylcellulose of tartaric acid), sorbitol, magnesium stearate, silicon dioxide, sodium cyclamate, the aroma of orange

Acidifier citric acid, acidity regulator sodium hydrogen carbonate, L-ascorbic acid, filler sorbitol, flavors, sweetener sodium cyclamate and sodium saccharin, dye riboflavin

Hansal multivit

Acidifier citric acid, acidity regulator sodium hydrogen carbonate, filler sorbitol, flavors, maize starch, L-ascorbic acid, maltodextrin, sweetener sodium cyclamate and sodium saccharin, DL-alphatocopheryl acetate, beetroot juice powder, nicotinamide, calcium-D-pantothenate, dye riboflavin pyridoxine hydrochloride, thiamine mononitrate, petroyl-mnoglutamic acid, D-biotin, cyanocobalamine

(D)

$\begin{array}{ll}11 & \text { Plivit C } \\ 12 & \text { Vitamin C } 1000\end{array}$

Acidifier citric acid, acidity regulator sodium hydrogen carbonate, L-ascorbic acid, filler sorbitol, inulin, starch, tricalcium phosphate, beetroot juice powder, sweetener sodium cyclamate, dye riboflavin

12 Vitamin C 1000

L-ascorbic acid, maize starch, talc, povidone, magnesium stearate

L-ascorbic acid, magnesium stearate, polyethylene glycol, silicon dioxide, hydroxypropyl methylcellulose, cellulose gel, citrus bioflavonoid complex (Citrus spp.) (20 mg, 10\%, $10 \mathrm{mg}$ hesperidin and rutin, rosehip $20 \mathrm{mg}$ )

13 Bio-C

L-ascorbic acid, thickener hydroxypropyl methylcellulose, maize starch, silicon dioxide, magnesium salts of fatty acids, color titanium dioxide, talk, olive oil, a complex of bioflavonoids from the peel of citrus fruit (Citrus spp.) (40 mg, 30\% flavonoids calculated as hesperidin)

$14 \quad$ Natural wealth

L-ascorbic acid, dicalcium phosphate, hypromellose, cellulose (plant origin), magnesium stearate, bioflavonoids from the peel of citrus fruit (Citrus spp.) (25 mg), wild Rosehips

$15 \quad$ Vit C alkaloid
Manufacturer

DM, Karlsruhe, Germany

Doppel Herz, Flensburg, Germany

DM, Karlsruhe, Germany

Hemofarm, Vrsac, Bosnia and Herzegovina

Nutrilo GmbH Germany

Esensa, Belgrade, Serbia

Farmalabor, Canosa di Puglia, Italy

Sanotact, GmbH Germany

Sanotact, GmbH Germany

Nutrilo GmBH Germany

Pliva, Zagreb, Croatia

Optimum, Alkmaar, The Netherlands

Dietpharm, Bestovje, Rakitje, Croatia

Wealth, Zagreb, Croatia);

Alkaloid, Skopje, North Macedonia 


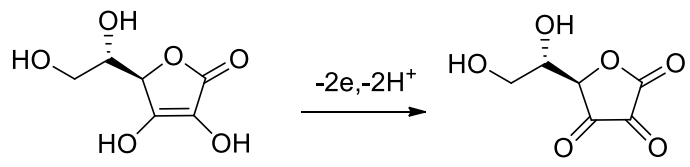<smiles>CC1=CC(=Cc2cc(C)c([O-])c(Br)c2)C=C(Br)C1=O</smiles><smiles>Cc1cc(C2(c3cc(C)c(O)c(Br)c3)OS(=O)(=O)c3ccccc32)cc(Br)c1O</smiles>

Fig. 1 Reaction between ascorbic acid and bromocresol purple

highest IF was found to be at the concentration value of $1 \times 10^{-5} \mathrm{~mol} \mathrm{~L}^{-1}$, (Fig. 3) whereas higher concentrations showed lower IFs, and with lower concentrations, it was not possible to construct the calibration curve.

\subsection{Calibration Curve, LOD and LOQ}

Under optimal conditions, the calibration curve was found to be linear in the concentration range of $A A$ from $4.65 \times 10^{-5}$ to $4.65 \times 10^{-6} \mathrm{~mol} \mathrm{~L}^{-1}$ with a determination coefficient of $\mathrm{R}^{2}=0.9964$, and the linear equation $y=-61.836 x+8.5902$. and recorded at $1 \% T$.

The linearity area is narrow, which is also a limitation of the method. The limit of detection was (LOD) $8.77 \times 10^{-7} \mathrm{~mol} \mathrm{~L}^{-1}$, (calculated as $3 \sigma$ ) and limit of quantification (LOQ) $2.35 \times 10^{-5} \mathrm{~mol} \mathrm{~L}^{-1}$, (calculated as $10 \sigma$ ) were determined using nine $(n=9)$ standard solutions of $A A$ of the same concentration $\left(2.48 \times 10^{-5} \mathrm{~mol} \mathrm{~L}^{-1}\right)$, by measuring their IFs. Measurement precision (expressed as RSD) was found to be $8.46 \%$ for this concentration.

The calibration curve was also recorded with the instrument parameter all filters opened. It was found to be linear in the concentration range from $4.77 \times 10^{-5}$ to $4.77 \times 10^{-6} \mathrm{~mol} \mathrm{~L}^{-1}$ with a determination coefficient of $\mathrm{R}^{2}=0.9809$, and the linear equation $\mathrm{y}-6 \times 10^{6}+981.28$ under the optimal condition Table 2.

\subsection{Reaction time}

The stability of the IF signal of Leuko-BCP concerning time was determined by measuring the reaction progression of an AA solution $\left(4.65 \times 10^{-4} \mathrm{~mol} \mathrm{~L}^{-1}\right)$ with the reagent for

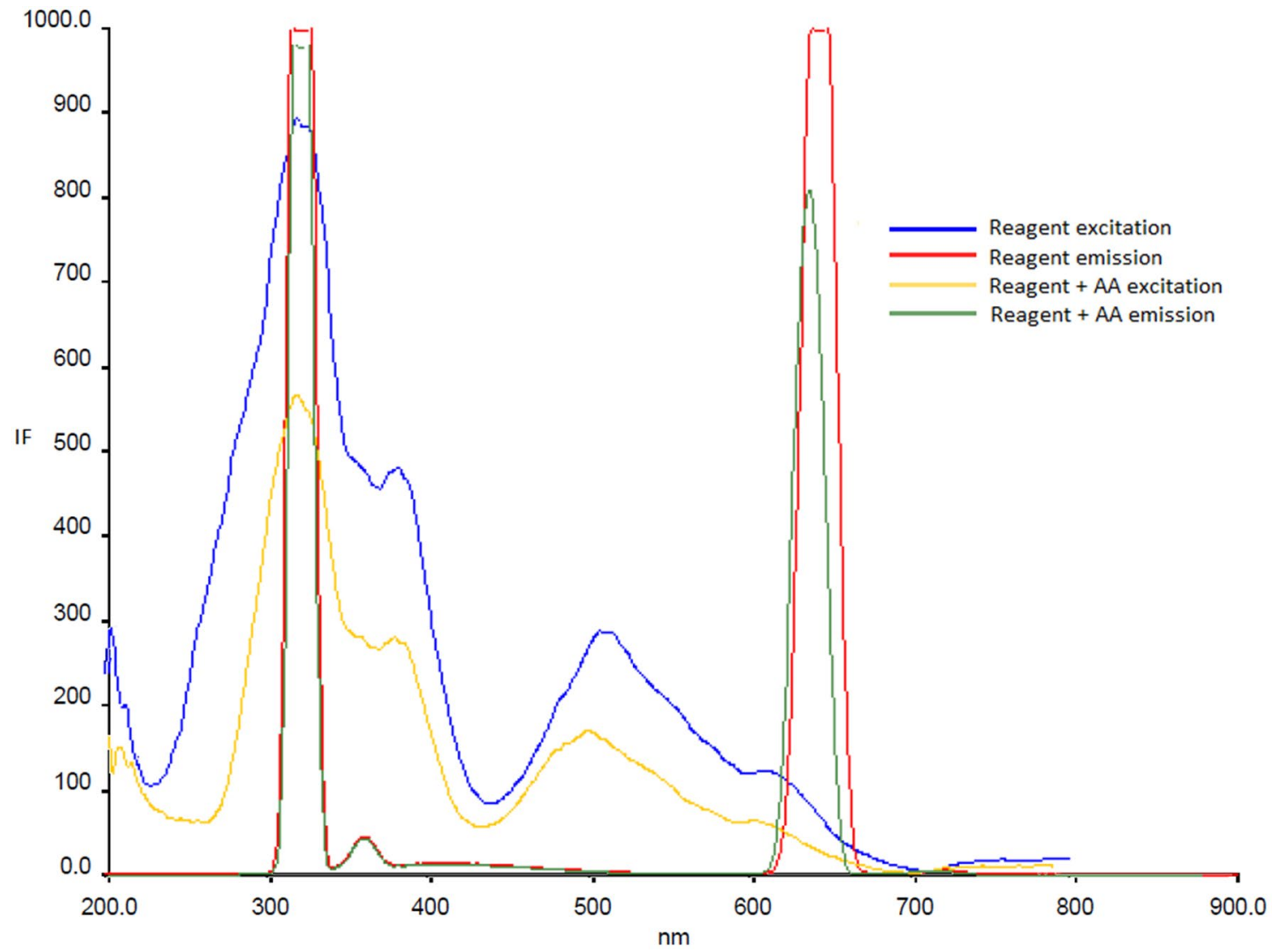

Fig. 2 Excitation and emission spectra of the reagent (phosphate buffer/BCP) without AA and with added AA 
Fig. 3 Effect of BCP concentration on the relative IF of the reaction system

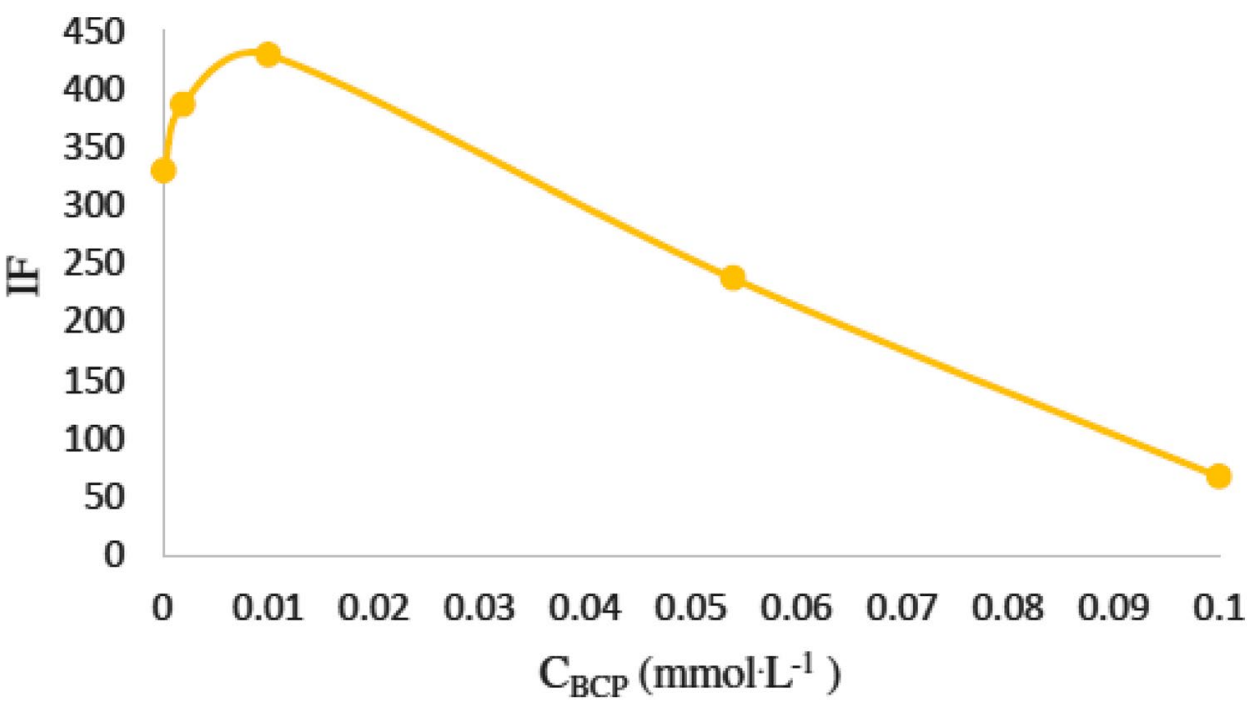

Table 2 Method analytical parameters

\begin{tabular}{ll}
\hline Parameters & Optimal condition \\
\hline Excitation wavelength & $318 \mathrm{~nm}$ \\
Emission wavelength & $641 \mathrm{~nm}$ \\
Concentration BCP & $1 \times 10^{-5} \mathrm{~mol} \mathrm{~L}^{-1}$ \\
Slit & $10 \mathrm{~mm}$ \\
Stability of signal & After $9 \mathrm{~min}$ \\
Linearity (1\%T) & $4.65 \times 10^{-5}$ to $4.65 \times 10^{-6} \mathrm{~mol} \mathrm{~L}^{-1}$ \\
Linearity (all filters open) & $4.77 \times 10^{-5}$ to $4.77 \times 10^{-6} \mathrm{~mol} \mathrm{~L}^{-1}$ \\
Linear Eq. (1\%T) & $y=-61.836 \mathrm{x}+8.5902$ \\
Linear equation (all filters open) & $\mathrm{y}=-6 \times 10^{6}+981.28$ \\
LOD & $8.77 \times 10^{-7} \mathrm{~mol} \mathrm{~L}^{-1}$ \\
LOQ & $2.35 \times 10^{-5} \mathrm{~mol} \mathrm{~L}^{-1}$ \\
SD & $2.097 \times 10^{-5} \mathrm{~mol} \mathrm{~L}^{-1}$ \\
RSD & $8.46 \%$ \\
\hline
\end{tabular}

$13 \mathrm{~min}$, and it was shown that the signal is stable $9 \mathrm{~min}$ after the reaction was initiated.

\section{Accuracy, precision, and repeatability}

The accuracy of this spectrofluorimetric method was assessed by analyzing AA solutions in the concentration range from $0.0480 \mathrm{mmol} \mathrm{L}^{-1}$ to $0.0058 \mathrm{mmol} \mathrm{L}^{-1}(n=10$ for each concentration) and by calculating SD, \%RSD, and Recovery values (Table 3 ), which showed satisfactory accuracy.

To estimate precision and repeatability, the IF of one newly-prepared AA solution $0.477 \mathrm{mmol} \mathrm{L}^{-1}$ was measured periodically, in four replicates with $n=10$ (Table 4). Obtained results were taken for calculating SD and \%RSD.
Table 3 Accuracy assessment results for standard AA solutions

\begin{tabular}{llllc}
\hline $\begin{array}{l}\text { Prepared } \\
\mathrm{C}_{\mathrm{AA}} \\
(\mathrm{mmol} / \mathrm{L})\end{array}$ & $\mathrm{IF} \pm \mathrm{SD}$ & $\begin{array}{l}\text { Calculated } \\
\mathrm{C}_{\mathrm{AA}}(\mathrm{mmol} / \mathrm{L})\end{array}$ & \%RSD & Recovery (\%) \\
\hline 0.0480 & $5.514 \pm 0.129$ & 0.0490 & 2.39 & 102.08 \\
0.0230 & $7.115 \pm 0.158$ & 0.0240 & 2.22 & 104.35 \\
0.0058 & $8.238 \pm 0.074$ & 0.0057 & 0.89 & 98.28 \\
\hline
\end{tabular}

Table 4 Precision and repeatability estimation results for one standard AA solution

\begin{tabular}{llllll}
\hline$\#$ & $\mathrm{C}_{\mathrm{AA}}(\mathrm{mmol} / \mathrm{L})$ & $\mathrm{IF} \pm \mathrm{SD}$ & $\% \mathrm{RSD}$ & $\begin{array}{l}\text { Average } \\
\mathrm{IF} \pm \mathrm{SD}\end{array}$ & $\begin{array}{l}\text { Average } \\
\% R S D\end{array}$ \\
\hline 1 & 0.477 & $7.08 \pm 0.15$ & 2.10 & $6.85 \pm 0.15$ & 2.19 \\
2 & 0.477 & $6.75 \pm 0.15$ & 2.22 & & \\
3 & 0.477 & $6.79 \pm 0.14$ & 2.06 & & \\
4 & 0.477 & $6.79 \pm 0.16$ & 2.36 & & \\
\hline
\end{tabular}

\section{Sample preparation}

The samples used for analysis were in different forms, with a different ascorbic acid content, and commercially available. Pharmaceutical samples (tablets, effervescent tablets, and one powdery form) were first weighed, then powdered in a mortar (except the powdery form of AA, sample). A suitable amount of powdered sample was dissolved in ultra-pure water in a $50.0 \mathrm{~mL}$ calibrated flask, which was the stock solution. Then further dilutions $(1: 10,1: 20,1: 100)$ were prepared with ultra-pure water in $10.0 \mathrm{~mL}$ calibrated flasks, which were the working sample solutions used for analysis. Simultaneously, the stock solution aliquots of 
$2.0 \mathrm{~mL}$ were centrifuged at $5000 \mathrm{rpm}$ for $10 \mathrm{~min}$ at $20^{\circ} \mathrm{C}$. After the samples were centrifuged, identical dilutions were made with ultra-pure water as with the non-centrifuged stock solution to prepare working solutions. The samples were further treated according to the procedure and optimized conditions $\mathrm{pH}$, the concentration of $\mathrm{BCP}$ reagent, time reaction, and instrumental parameters. Samples were measured in different concentrations (1:10, 1:20, 1:100), centrifugated and non-centrifugated, immediately after cooling and $30 \mathrm{~min}$ after, and with all filters open and $1 \% \mathrm{~T}$. The results were calculated from a two-calibration curve using $A A$ as a standard. Results are presented in Table 5.

Samples containing zinc (samples 1 and 2) must be centrifuged and analyzed $30 \mathrm{~min}$ after the reaction. Sample 1 contains fluorescent riboflavin and it requires analysis with $1 \% \mathrm{~T}$. The dilution corresponding to this type of sample is 1:10. Samples 3 (containing iron(II) lactate), sample 4 (containing paracetamol), and sample 5 (also containing other vitamins-multivitamin) require to be centrifuged, diluted 1:10, and analyzed after $30 \mathrm{~min}$ with $1 \% \mathrm{~T}$. Sample 6 requires to be centrifuged because it contains cellulose and talc which can interfere with the analysis if not precipitated. It requires a 1:20 dilution and is analyzed with $1 \% \mathrm{~T}$.

Samples 8 and 9 can be analyzed without centrifugation immediately after the completing of the reaction. Sample 4 was diluted 1:10 and analyzed with all filters opened.

Samples 5 and 9 are multivitamins, but sample 5 requires centrifugation because it contains inulin which is not well soluble in water, i.e., its solubility changes with temperature $[26,27]$. The difference in the analysis is that sample 5 , which is multivitamin and contains a small amount of ascorbic acid (40 mg/tablet) should be diluted in a ratio of 1:20 and analyzed with $1 \% \mathrm{~T}$ due to the influence of other vitamins present in the sample. Samples 10 and 11 must be centrifuged before analysis because they contain inulin and talc which may limit the analysis especially in sample 11 where the AA content is lower. Also, both samples are diluted at 1:10. Sample 6 was also diluted at 1:20, centrifuged, and $30 \mathrm{~min}$ after the reaction was complete with all filters open. A sample of vitamin C containing $20 \mathrm{mg}$ or less of bioflavonoids and 40 times more ascorbic acid was analyzed at a 1:10 dilution and in all filters open. Samples containing more than $20 \mathrm{mg}$ of bioflavonoids must be diluted at 1:20 and worked with $1 \% \mathrm{~T}$. The ascorbic acid content is 20 times higher than the bioflavonoid content.

Sample 15 could not be analyzed by the proposed method, even after centrifugation and dilution. It is believed that in addition to containing microcrystalline cellulose and magnesium stearate, it also contains croscarmellose sodium, which is cross-linked carboxymethyl cellulose. The crosslinking of carboxymethyl cellulose reduces the solubility in water, and at the same time allows the material to swell and absorb multiple weights in water. As a result, it provides superior drug dissolution and disintegration characteristics, thus improving the bioavailability of the formulas by bringing the active ingredients into better contact with body fluids. Its purpose in most pills, including dietary supplements, is to help the pill break down quickly in the gastrointestinal tract. If the tablet disintegrant is not included, the tablet may break down too slowly, in the wrong part of the gut, thus reducing the effectiveness and bioavailability of the active ingredients.
Table 5 Results of analysis of pharmaceutical samples determined by the developed method and by the iodine titration

\begin{tabular}{llccrrr}
\hline Sample & $\begin{array}{l}\text { Proposed } \\
\text { method }(\mathrm{mg} \mathrm{AA} / \\
\text { tablet) }\end{array}$ & $\begin{array}{l}\text { Labeled value } \\
(\mathrm{mg} \mathrm{AA} \text { tablet) }\end{array}$ & Titration with lodine $(\mathrm{mg})$ & Recovery $(\%)$ & P test & T test \\
\hline 1 & $390.51 \pm 0.06$ & 400 & $576.50 \pm 0.07$ & 97.62 & 0.0005 & 4.85 \\
2 & $470.49 \pm 0.25$ & 500 & $486.80 \pm 0.07$ & 94.09 & 0.4790 & 0.78 \\
3 & $134.35 \pm 0.08$ & 134 & $81.50 \pm 0.001$ & 100.26 & 0.5671 & 0.59 \\
4 & $201.62 \pm 0.08$ & 200 & $198.40 \pm 0.07$ & 100.81 & 0.1191 & 1.88 \\
5 & $48.76 \pm 0.29$ & 60 & $66.10 \pm 0.07$ & 81.26 & 0.0001 & 1.84 \\
6 & $462.07 \pm 0.12$ & 500 & $442.20 \pm 0.07$ & 92.41 & 0.2454 & 1.36 \\
7 & $1210.34 \pm 0.18$ & 1000 & $1175.38 \pm 0.07$ & 121.03 & 0.0007 & 0.53 \\
8 & $257.62 \pm 12.60$ & 240 & $331.30 \pm 0.21$ & 107.34 & 0.0001 & 9.37 \\
9 & $44.63 \pm 0.92$ & 40 & $116.00 \pm 0.35$ & 111.58 & 0.0003 & 5.25 \\
10 & $224.58 \pm 0.08$ & 250 & $268.00 \pm 0.14$ & 89.83 & 0.0001 & 21.24 \\
11 & $47.15 \pm 0.18$ & 50 & $44.18 \pm 0.07$ & 94.30 & 0.7650 & 0.53 \\
12 & $906.94 \pm 6.57$ & 1000 & $1351.20 \pm 0.07$ & 90.67 & 0.0297 & 3.31 \\
13 & $631.88 \pm 0.13$ & 500 & $537.18 \pm 0.07$ & 126.38 & 0.0013 & 5.80 \\
14 & $646.04 \pm 0.13$ & 500 & $437.86 \pm 0.07$ & 129.21 & 0.0029 & 6.48 \\
15 & $1082.84 \pm 1.56$ & 500 & $533.47 \pm 0.07$ & 216.57 & 0.0001 & 36.21 \\
\hline
\end{tabular}


Samples containing talc, inulin, cellulose, magnesium salts of fatty acids (in the form of magnesium stearate) require centrifugation before analysis. Samples containing hydroxypropylmethylcellulose do not require centrifugation because this form of cellulose is soluble in water. Multivitamin samples must be analyzed at $1 \%$ T. Samples containing zinc, iron, paracetamol should be diluted 1:10, centrifuged, and analyzed at $1 \% \mathrm{~T}$.

Examination of the influence of individual interferences that can be found in pharmaceutical samples confirmed that additional components that are in addition to ascorbic acid must be taken into account because the preparation of the sample and the analysis itself depend on it.

Results obtained with the proposed method show good agreement with those obtained by the titrimetric method and the amount of AA stated on the declarations provide by the manufacturers, of simpler composition.

The content of AA for the sample that contains bioflavonoids calculated as hesperidin (Bio-C), samples 13 and 14 , was higher than the result obtained by the titrimetric method. For sample 4 that contained paracetamol and some additional components, the content of AA measured with the proposed method is in agreement with the content of $A A$ according to the labeled value. The presence of $Z n$ in the investigated sample showed an impact on the relative fluorescence intensity. The AA content results in samples (samples 1 and 2) were higher than that obtained by titration.

Based on this data, the influence of bioflavonoids, metals such as zinc, iron, calcium, and magnesium in form of their salts, paracetamol, and folic acid on the relative fluorescence intensity were examined (Table 6).

\section{Interferences}

Rutin and hesperidin as citrus bioflavonoides, calcium carbonate, magnesium carbonate, citric acid, paracetamol, zinc chloride, folic acid, and iron(II) sulfate were investigated as possible interfering agents. By evaluating standard solutions of AA at one concentration of three different concentrations of the interfering substances, the effect of probable interfering substances on the relative intensity of the fluorescence signal of bromocresol purple was investigated. The concentrations of possible interfering substances were the same, higher, or lower than AA concentrations (Table 6). All of these chemicals can be detected as ingredients or other components in pharmaceutical samples alongside AA. The concentrations of most possible interfering substances were greater than those present in pharmaceutical samples.
Table 6 Influence of interferences on the relative intensity of fluorescence for the determination of ascorbic acid.

\begin{tabular}{|c|c|c|}
\hline Interfering substance & $\begin{array}{l}\text { Concentration } \\
\left(\mathrm{mol} \mathrm{L}^{-1}\right)\end{array}$ & Change in signal (\%) \\
\hline \multirow[t]{3}{*}{ Rutin } & $1 \times 10^{-2}$ & -99.06 \\
\hline & $1 \times 10^{-3}$ & -94.35 \\
\hline & $1 \times 10^{-4}$ & -21.07 \\
\hline \multirow[t]{3}{*}{ Hesperidine } & $1 \times 10^{-3}$ & +66.33 \\
\hline & $1 \times 10^{-4}$ & +0.55 \\
\hline & $1 \times 10^{-5}$ & +35.89 \\
\hline \multirow[t]{3}{*}{ Citric acid } & $1 \times 10^{-2}$ & +14.95 \\
\hline & $1 \times 10^{-3}$ & +30.55 \\
\hline & $1 \times 10^{-4}$ & +6.73 \\
\hline \multirow[t]{3}{*}{ Folic acid } & $1 \times 10^{-2}$ & -99.49 \\
\hline & $1 \times 10^{-3}$ & -93.24 \\
\hline & $1 \times 10^{-4}$ & -32.78 \\
\hline \multirow[t]{2}{*}{ Zinc chloride } & $1 \times 10^{-3}$ & +112.99 \\
\hline & $1 \times 10^{-4}$ & -0.88 \\
\hline \multirow[t]{2}{*}{ Iron (II) sulphate } & $1 \times 10^{-6}$ & -23.28 \\
\hline & $1 \times 10^{-7}$ & -17.78 \\
\hline \multirow[t]{3}{*}{ Paracetamol } & $1 \times 10^{-2}$ & +200.40 \\
\hline & $1 \times 10^{-3}$ & +8.26 \\
\hline & $1 \times 10^{-4}$ & +36.46 \\
\hline \multirow[t]{2}{*}{ Calcium carbonate } & $1 \times 10^{-3}$ & -2.99 \\
\hline & $1 \times 10^{-4}$ & +35.48 \\
\hline \multirow[t]{3}{*}{ Magnesium carbonate } & $1 \times 10^{-2}$ & -5.27 \\
\hline & $1 \times 10^{-3}$ & +7.73 \\
\hline & $1 \times 10^{-4}$ & -18.49 \\
\hline
\end{tabular}

From the results presented in Table 6, it is clear that interfering substances like bioflavonoids or metals could interfere with the fluorescence intensity and give the wrong results on the quantity of AA. Paracetamol, folic acid, bioflavonoids show to have a major impact on signal intensity. Other investigated substances were investigated in a higher concentration than those which are actually present in the sample of AA. The interfering activity of magnesium carbonate, or some other type of magnesium salts like magnesium salts of fatty acids, calcium carbonate could be prevented by centrifugation or by diluting the sample unlike bioflavonoids, $\mathrm{Zn}$, Fe, etc., which required some other different treatments.

\section{Discussion}

The purpose of this paper is to develop a new spectrofluorimetric method for the determination of ascorbic acid in pharmaceutical samples because spectrofluorimetry is a simple, low-cost, sensitive method that enables the measurement of low concentrations of the test analyte. After 
optimizing the method, which required testing different conditions under which the reaction between $A A$ and $B C P$ takes place, the goal was to test the method on as many pharmaceutical preparations containing various additional components besides AA.

To achieve the goal, the method was tested on fifteen different samples having different AA content as well as additional components including bioflavonoids, iron, zinc, cellulose, citric acid, folic acid, paracetamol, etc. All samples were tested without prior preparation as well. with prior preparation involving centrifugation. Samples were analyzed with $1 \% \mathrm{~T}$ or with all filters open, as well as immediately after incubation and $30 \mathrm{~min}$ after incubation. Also, samples were prepared in three different dilutions to reduce the effect of interference, which was also subsequently examined. Since there is no universal method for all types of samples, this method also has its limitations and requirements related to sample preparation and analysis. Linearity area is narrow, which represents a limitation of this method and requires that samples be prepared in such a narrow concentration range. Samples that contain iron, zinc, paracetamol, magnesium salts like magnesium salts of fatty acids, cellulose, talc, inulin demand to be centrifugated before analysis. In samples that contain hydroxypropylmethylcellulose, it is not necessary to be centrifugated because this form of cellulose is soluble in water. Samples that contain bioflavonoids and riboflavin must be analyzed with $1 \% \mathrm{~T}$ because these components tend to fluoresce. Multivitamin samples must be analyzed at $1 \%$ T. Finally, samples that have a smaller amount of $\mathrm{AA}$, and a lot of additional components are required to be diluted in ratio 1:20 so the influence of additional components can be reduced.

Table 7 compares performance characteristics such as linearity range and limit of detection reported spectrofluorimetric methods. It is visible that some of the methods have a narrow linear range while others have a wider. Comparing the proposed method with other methods in the literature in terms of the field of linearity $[14,28$, 29] the proposed method does not have a wide field of

Table 7 Comparison between previously reported spectrofluorimetric methods for the determination of ascorbic acid and the proposed method

\begin{tabular}{|c|c|c|c|c|c|}
\hline Reagent(s) Used & $\lambda_{\mathrm{ex}} \mathrm{i} \lambda_{\mathrm{em}}(\mathrm{nm})$ & $\begin{array}{l}\text { Linearity } \\
\text { range ( } \mu \mathrm{mol} \\
\left.\mathrm{L}^{-1}\right)\end{array}$ & $\operatorname{LOD}\left(\mu \mathrm{mol} \mathrm{L}{ }^{-1}\right)$ & Samples & References \\
\hline 2,3-Diaminonaphthalene & 400,520 & $11-1700$ & 2.27 & Pharmaceutical samples & [28] \\
\hline 1,2-Diamino-4,5-dimethoxybenzene & 370,458 & $7.3-1130$ & 0.0051 & Blood serum & [17] \\
\hline Cerium(IV) ion & 303,340 & $0.1-8.0$ & 0.016 & Pharmaceutical samples & {$[21]$} \\
\hline $\begin{array}{l}\text { Mono-3-[6-N(4-carboxyphenyl)]- } \\
\text { beta-cyclodextrin }\end{array}$ & 280,352 & $0.28-450$ & 0.068 & Real samples & [22] \\
\hline o-Phenylenediamine & 360,430 & $1.0-5.6$ & nd & $\begin{array}{l}\text { Beer, wine, urine and pharmaceutical } \\
\text { samples }\end{array}$ & {$[28]$} \\
\hline o-Phenylenediamine & 356,440 & $11-567$ & 7.38 & Pharmaceutical samples & [29] \\
\hline o-Phenylenediamine & 360,430 & $\begin{array}{l}0.5-170 \\
0.3-230\end{array}$ & $\begin{array}{l}0.113 \\
0.034\end{array}$ & $\begin{array}{l}\text { Pharmaceutical samples, non-alcoholic } \\
\text { beverages and blood serum }\end{array}$ & {$[19,22,30]$} \\
\hline $\mathrm{Ti}(\mathrm{III})$ & 227,419 & $1-10$ & 0.8 & $\begin{array}{l}\text { Real samples (leon juice, hematinic } \\
\text { capsule, shampoo) }\end{array}$ & [31] \\
\hline Methylene blue & 664,682 & $0.3-6$ & 0.25 & Pharmaceutical samples & {$[15,32]$} \\
\hline Methylene blue & 660,694 & $0.6-230$ & 1.3 & Non-alcoholic beverages & [33] \\
\hline Methylene blue & 664,686 & $5.68-45.42$ & 1.124 & $\begin{array}{l}\text { Tablet, sweetlet, effervescent tablet, } \\
\text { and ready to drink product }\end{array}$ & [34] \\
\hline Pyronine Y & 516,554 & $0.13-2.0$ & 0.068 & $\begin{array}{l}\text { Pharmaceutical samples, fruits, vegeta- } \\
\text { bles and juices }\end{array}$ & [16] \\
\hline $\mathrm{TPTZ} \mathrm{i} \mathrm{FeCl}_{3}$ & 393,790 & $5.4-540$ & 0.77 & Pharmaceutical samples & [14] \\
\hline Acriflavine & 265,505 & $11.36-56.78$ & 0.4542 & $\begin{array}{l}\text { Pharmaceutical nutritional supple- } \\
\text { ments }\end{array}$ & {$[35]$} \\
\hline L-tyrosine & 275,300 & $0.03-30$ & 0.01 & $\begin{array}{l}\text { Tablets, injections, effervescent tablet, } \\
\text { chewable tablets, multivitamine } \\
\text { formula with mineras }\end{array}$ & [36] \\
\hline Thiamina and potassium ferricyanide & 367,441 & $0.086-1.5$ & 0.026 & Tablets and juices & [37] \\
\hline Bromocresol purple & 318,641 & $\begin{array}{l}4.65-46.5 \\
4.77-47.7\end{array}$ & 0.877 & Pharmaceutical samples & Present $\mathrm{u}$ \\
\hline
\end{tabular}

The bold values represent the characteristics of the proposed method 
linearity Table 2, which is also its biggest limitation. The detection limit Table 7 is also not better than few other proposed methods [14-16, 21, 29, 31] for the determination of AA in pharmaceutical samples. However, this method is promising for the simple and relative rapid determination of AA. It can be applied to many pharmaceutical samples containing various additional components..

\section{Conclusions}

For the quantification of ascorbic acid, a variety of spectrophotometric and spectrofluorimetric methods are routinely utilized. They're utilized in the regular analysis since they're typically simple, operative, quick, cheap, and sensitive. Because there is no single method for all types of samples, each documented method, including this one, finds use for a different type of sample, which necessitates a different type of sample, which demands a new form of sample preparation.

The proposed approach is simple to use and has a high sensitivity. Except for samples that include interfering compounds that must be eliminated before analysis, sample preparation is simple. Depending on the additional components present in the sample, the sample will be processed and evaluated differently. The method has the benefit of being able to be used on a large number of pharmaceutical samples. The method showed good precision and repeatability as well as satisfactory recovery values in terms of accuracy. A limitation of the method is the narrow linearity range. To our knowledge, there are no other reports on the spectrofluorimetric method for estimating AA content with bromocresole purple.

Further research could include applying this method to the real samples or trying to add some components or metal ions that could affect on the reaction to achieve better reproducibility, reaction rate, better linearity range, and maybe reduce sample preparation.

Author's contribution All authors have participated in this research, either by conception and design or analysis and interpretation of the data; drafting the article, or revising it critically for important intellectual content.

Availability of data and material On the request from the corresponding author.

Code availability Not applicable.

\section{Declarations}

Conflict of interest The authors declare that they have no conflict of interest.
Open Access This article is licensed under a Creative Commons Attribution 4.0 International License, which permits use, sharing, adaptation, distribution and reproduction in any medium or format, as long as you give appropriate credit to the original author(s) and the source, provide a link to the Creative Commons licence, and indicate if changes were made. The images or other third party material in this article are included in the article's Creative Commons licence, unless indicated otherwise in a credit line to the material. If material is not included in the article's Creative Commons licence and your intended use is not permitted by statutory regulation or exceeds the permitted use, you will need to obtain permission directly from the copyright holder. To view a copy of this licence, visit http://creativecommons. org/licenses/by/4.0/.

\section{References}

1. Padayatty SJ, Katz A, Wang $\mathrm{Y}$, Eck $\mathrm{P}$, Kwon O, Lee JH, Chen $\mathrm{S}$, Corpe C, Dutta A, Dutta SK, Levine M (2003) Vitamin C as an antioxidant: evaluation of its role in disease prevention. J Am Coll Nutr 22(1):18-35. https://doi.org/10.1080/07315724.2003. 10719272

2. Abdel-Hamid ME, Barary MH, Hassan EM, Elsayed MA (1985) Spectrophotometric determination of ascorbic acid and thiamine hydrochloride in pharmaceutical products using derivative spectrophotometry. Analyst 110(7):831. https://doi.org/10. 1039/an9851000831

3. Abdelmageed O, Khashaba PY, Askal HF, Saleh GA, Refaat IH (1995) Selective spectrophotometric determination of ascorbic acid in drugs and foods. Talanta 42(4):573-579. https://doi.org/ 10.1016/0039-9140(95)01449-I

4. De Quadros L, Brandao I, Longhi R (2016) Ascorbic acid and performance: a review. Vitamins \& Minerals, 5(136):1318-2376 https://doi.org/10.4172/2376-1318.1000136

5. Moskowitz A, Andersen LW, Huang DT, Berg KM, Grossestreuer AV, Marik PE, Sherwin RL, Hou PC, Becker B, Cocchi MN, Doshi P, Gong J, Sen A, Donnino MW (2018) Ascorbic acid, corticosteroids, and thiamine in sepsis: a review of the biologic rationale and the present state of clinical evaluation. Crit Care 22(1):1-7. https://doi.org/10.1186/s13054-018-2217-4

6. Pisoschi AM, Danet AF, Kalinowski S (2008) Ascorbic acid determination in commercial fruit juice samples by cyclic voltammetry. J Autom Methods Manag Chem 2008:1-8. https://doi.org/ 10.1155/2008/937651

7. Kumar K, Mishra A, Sheikh AA, Patel P, Ahirwar MK, Showkeen M. Bashir AA (2017) Effect of ascorbic acid on some biochemical parameters during heat stress in commercial broilers. Int J Curr Microbiol App Sci 6(11): 5425-5434, https://doi.org/10.20546/ ijcmas.2017.611.519

8. Sunil Kumar BV, Singh S, Verma R (2015) Anticancer potential of dietary vitamin $D$ and ascorbic acid: A review. Crit Rev Food Sci Nutr 57(12):2623-2635. https://doi.org/10.1080/10408398.2015. 1064086

9. Jutkus RAL, Li N, Taylor LS, Mauer LJ (2015) Effect of temperature and initial moisture content on the chemical stability and color change of various forms of vitamin C. Int J Food Prop 18(4):862879. https://doi.org/10.1080/10942912.2013.805770

10. Hormozi Nezhad, MR, Karimi MA, Shahheydari F (2010) A sensitive colorimetric detection of ascorbic acid in pharmaceutical products based on formation of anisotropic Silver nanoparticles. Sci Iran Trans F Nano 17: 148-153 https://www.sid.ir/en/journal/ ViewPaper.aspx?id=201601

11. Kapur A, Hasković A, Čopra-Janićijević A, Klepo L, Topčagić A, Tahirović I, Sofić E (2012) Spectrophotometric analysis of total 
ascorbic acid content in various fruits and vegetables. Glas hem tehnol Bosne Herceg 38: 39-42, http://pmf.unsa.ba/hemija/ glasnik/files/Issue\%2038/38\%20-\%208-Kapur.pdf

12. Lau O-W, Luk S-F, Wong K-S (1986) Background correction method for the determination of ascorbic acid in soft drinks, fruit juices and cordials using direct ultraviolet spectrophotometry. Analyst 111(6):665. https://doi.org/10.1039/an9861100665

13. Salkić M, Selimović A (2015) Spectrophotometric determination of $\mathrm{L}$-ascorbic acid in pharmaceuticals based on its oxidation by potassium peroxymonosulfate and hydrogen peroxide. Croat Chem Acta 88(1):73-79. https://doi.org/10.5562/cca2551

14. Klepo L, Copra-Janicijevic A, Kukoc-Modun L (2016) A new indirect spectrofluorimetric method for determination of ascorbic acid with 2,4,6-Tripyridyl-S-Triazine in pharmaceutical samples. Molecules 21(1):1-12. https://doi.org/10.3390/molecules210101 01

15. Dilgin $Y$, Nişli G (2005) Fluorimetric determination of ascorbic acid in Vitamin $C$ tablets using methylene blue. Chem Pharm Bull 53(10):1251-1254. https://doi.org/10.1248/cpb.53.1251

16. Feng S, Wang J, Chen X, Fan J (2005) Kinetic spectrofluorimetric determination of trace ascorbic acid based on its inhibition on the oxidation of pyronine $Y$ by nitrite. Spectrochim Acta A Mol Biomol Spectrosc Spectrochim Acta A 61(5):841-844. https:// doi.org/10.1016/j.saa.2004.06.008

17. Iwata T, Hara S, Yamaguchi M, Nakamura M, Ohkura Y (1985) An ultramicro fluorimetric determination of total ascorbic acid in human serum using 1,2-diamino-4,5-dimetoxybenzene. Chem Pharm Bull 33(8):3499-3502. https://doi.org/10.1248/cpb.33. 3499

18. Mori K, Kidawara M, Iseki M, Umegaki C, Kishi T (1998) A simple fluorometric determination of vitamin C. Chem Pharm Bull (Tokyo) 46(9):1474-1476. https://doi.org/10.1248/cpb.46.1474

19. Pérez-Ruiz T, Martínez-Lozano C, Tomás V, Fenol J (2001) Fluorimetric determination of total ascorbic acid by a stopped-flow mixing technique. Analyst 126(8):1436-1439. https://doi.org/ 10.1039/b102458m

20. Wang L, Zhang L, She S, Gao F (2005) Direct fluorimetric determination of ascorbic acid by the supramolecular system of AA with beta-cyclodextrin derivative. Spectrochim Acta A Mol Biomol Spectrosc Spectrochim acta A 61:2737-2740. https://doi.org/ 10.1016/j.saa.2004.09.028

21. Wang R, Liu Z, Cai R, Li X (2002) A new spectrofluorimetric method for the determination of ascorbic acid based on its activating effect on hemoglobyn-catalyzed reaction. Anal Sci 18:977-980. https://doi.org/10.2116/analsci.18.977

22. Wu X, Diao Y, Sun C, Yang J, Wang Y, Sun S (2003) Fluorimetric determination of ascorbic acid with o-phenylenediamine. Talanta 59(1):95-99. https://doi.org/10.1016/s0039-9140(02) 00475-7

23. Council of Europe, European Pharmacopoeia Commission (2008) European Pharmacopoeia, 8.0 Strasbourg. 1590.

24. Elgailani IEH, Alghamdi RH (2017) Determination of vitamin C in some pharmaceutical dosage by UV-visible spectrophotometer using bromocresol purple as a chromogenic reagent. Der Pharma Chemica, 16: 28-32. https://scholar.google.com/citat ions? user $=$ WtjJnvkAAAAJ\&hl=en

25. Zhang R, Liu S, Wang L, Yang G (2013) Electroanalysis of ascorbic acid using poly(bromocresol purple) film modified glassy carbon electrode. Measurement 46(3):1089-1093. https://doi. org/10.1016/j.measurement.2012.11.007

26. Naskar B, Dan A, Ghosh S, Moulik SP (2010) Viscosity and solubility behavior of the polysaccharide inulin in water, Water +
Dimethyl Sulfoxide, and Water + Isopropanol media. J Chem Eng Data 55(7):2424-2427

27. Glibowski P, Bukowska A (2011) The effect of $\mathrm{pH}$, temperature and heating time on inulin chemical stability, Acta Sci Pol Technol Aliment 10(2): 189-196, https://www.food.actapol.net/ pub/5_2_2011.pdf

28. Huang H, Cai R, Du Y, Zeng Y (1995) Flow-injection stopped-flow spectrofluorimetric kinetic determination of total ascorbic acid based on an enzyme-linked coupled reaction. Anal Chim Acta 309:271-275. https://doi.org/10.1016/0003-2670(95)00056-6

29. Pérez-Ruiz T, Martínez-Lozano C, Sanz A, Guillén A (2004) Successive determination of thiamine and ascorbic acid in pharmaceuticals by flow injection analysis. J Pharm Biomed Anal J Pharmaceut Biomed 34:551-557. https://doi.org/10.1016/ s0731-7085(03)00606-x

30. Chung HK, Ingle JD Jr (1991) Fluorimetric kinetic method for the determination of total ascorbic acid with o-phenylenediamine. Anal Chim Acta 243:89-95. https://doi.org/10.1016/S00032670(00)82544-1

31. Rezaei B, Ensafi AA, Nouroozi S (2005) Flow-injection determination of ascorbic acid and cysteine simultaneously with spectrofluorometric detection. Anal Sci 21:1067-1071. https://doi.org/ 10.2116/analsci.21.1067

32. Briga M, Delic D, Copra-Janicijevic A, Klepo L, Sofic E, Topcagic A, Tahirovic I (2012) Fluorimetric determination of ascorbic acid using methylene blue, 7th CMAPSEEC, Conference on Medicinal and Aromatic Plants of Southeast European Countries, Proceedings, 104-109. https://scholar.google.com/citations?hl=en\& user $=1$ tpkQGEAAAAJ

33. Sheng L, Wang H, Han X (2008) Determination of ascorbic acid by fluorescence quenching method with methylene blue. Chinese J Anal Chem 27:67-69

34. Permana B, Ronauli D, Nugrahani I. (2021) Development and validation of spectrofluorimetric method for the determination of ascorbic acid in several dosage forms by using methylene blue. Acta Pharmaceutica Indonesia, 46(1), 1-6. https://journ als.itb.ac.id/index.php/acta/article/view/14917

35. Abd Ali LI, Qader AF, Salih MI, Aboul-Enein HY (2019) Sensitive spectrofluorometric method for the determination of ascorbic acid in pharmaceutical nutritional supplements using acriflavine as a fluorescence reagent. Luminescence. https://doi.org/ 10.1002/bio.3589

36. Wu Y, Chen Q, Zhao L, Du D, Guo N, Ren H, Liu W (2020) Spectrofluorometric method for the determination of ascorbic acid in pharmaceutical preparation using I-tyrosine as fluorescence probe. Luminescence. https://doi.org/10.1002/bio.3821

37. Duan R, Jiang J, Liu S, Yang J, Zhu J, Qiao M, Yan J, Hu X (2016) Spectrofluorometric determination of ascorbic acid using thiamine and potassium ferricyanide. Instrum Sci Technol 45(3):312-323. https://doi.org/10.1080/10739149.2016.12420 77

38. Yang J, Tong C, Jie N, Zhang G, Ren X, Hu J (1997) Fluorescent reaction between ascorbic acid and DAN and its analytical application. Talanta 44:855-858. https://doi.org/10.1016/s00399140(96)02129-7

Publisher's Note Springer Nature remains neutral with regard to jurisdictional claims in published maps and institutional affiliations. 